\title{
A SURVEY ON TEMPORAL CYCLIC PATTERNS
}

\author{
Vishal Hingmire ${ }^{1}$, Sheetal Girase ${ }^{2}$ \\ ${ }^{1}$ Student, Department of Information Technology, Maharashtra Institute of Technology, Savitribai Phule Pune \\ University, Pune, Maharashtra, India \\ ${ }^{2}$ Assistant Professor, Department of Information Technology, Maharashtra Institute of Technology, Savitribai Phule \\ Pune University, Pune, Maharashtra, India
}

\begin{abstract}
In a location based social networking there are many users who share their information socially and use of location based social networking site is increasing rapidly. So from any location user can share his/her place on social networking site. So other people come to know about some special places on social site. So from this information which he/she shares on social networking site as per specific time, there can be generation of pattern. When one person shares visited place on social networking site, then other peoples in his/her network can see that and can follow that place as per their requirement. So pattern about user's behavior can be find out by collecting information that he shares on social networking site. From collected information user's need and interest can be find out by finding specific pattern.
\end{abstract}

Key Words: Location based social networking, Temporal cyclic patterns, Location prediction, Temporal-Spatial, GeoSocial Correlation, Recommendation

\section{INTRODUCTION}

Temporal pattern gives lot of information about user's behavior as per time. From the behavioral pattern of user there can be prediction of his/her next action. The research on user's behavior about visiting places and mobile data for location prediction can be beneficial in many areas such as advertising and disaster relief [3]. Social networking site gives information about the behavioral pattern of user as he/she shares it on social networking site.

\section{TEMPORAL CYCLIC PATTERNS}

When a mobile user search for specific place or if he/she check-in at some restaurant or Movie theatre at specific time repeatedly so that there will be creation of temporal cyclic pattern for his behavior. If during a lunch time between 12.30 to 02.00 pm user search for Restaurant, on a week end user search for movie theatre, so that it will create a temporal cyclic pattern. Suppose on each month's first week user search for nearby malls, so that pattern will be monthly. Also there patterns that are weekly, daily and yearly. Suppose in a year many people search for travel points. So this information can be used for the recommendation of Point of Interests (POI).

There is modelling for temporal effects of user behavior in terms of temporal preferences and temporal correlations [4]. This information about user's mobile behavior can be gathered through check-in data. There are sites such as Facebook and Foursquare that gives location data about user using check-in. In [4] there are three major aspects that are:

1) Temporal Preference.

2) Temporal social Correlation.

3) Temporal-Spatial Correlation.

\subsection{Types}

There can be discovery of patterns as per application such as [1]:

1) Temporal Pattern

2) Occurrence Probabilistic Temporal Pattern

3) Duration Probabilistic temporal pattern

In occurrence probabilistic temporal pattern there is probability about the occurrence and it can be used for prediction. Correlation between two intervals can be there using probabilistic temporal pattern.

Also there can be periodic patterns for user's behaviour, user who has a strict timetable then at that time it is very easy to predict next location [6]. Using a combination of spatial and temporal approaches there can be increase in prediction accuracy.

\subsection{Algorithms}

As in [1] there are algorithms that are as follows:

1) Temporal Pattern Miner

2) Probabilistic temporal pattern miner

3) H-DFS

4) IEMiner

\section{METHODOLOGIES}

If there is series about visits such as visits in previous time, latest visit and time with next visit, then location prediction problem described as finding probability [3]:

$\mathrm{P}\left(\mathrm{v}_{\mathrm{i}}=1 \mid \mathrm{t}_{\mathrm{i}}=\mathrm{t}, \mathrm{v}_{\mathrm{i}-1}=\mathrm{l}_{\mathrm{k}}\right)$

Where $v_{i}=1$ denotes the $\mathrm{i}^{\text {th }}$ visit at location $1, t_{i}=t$ indicates the $i^{\text {th }}$ visit happen at time $t$ and $v_{i-1}=l_{k}$ indicates the $(i-1)^{\text {th }}$ visit at location $l_{k}$. Here $t$ is time which can be hour, month 
or even a year. The location 1 with higher probability will be the prediction of the $\mathrm{i}^{\mathrm{th}}$ visit.

Now by using Bayes rule, the probability in equation (1) is equal to:

$$
\begin{aligned}
& P\left(v_{i}=1 \mid t_{i}=t, v_{i-1}=l_{k}\right) \\
& =P\left(v_{i}=1\left|t_{i}=t\right| v_{i-1}=l_{k}\right) / p\left(t_{i}=t\right) \\
& \propto P\left(v_{i}=1, t_{i}=t \mid v_{i-1}=l_{k}\right) \\
& =P\left(t_{i}=t \mid v_{i}=1, v_{i-1}=l_{k}\right) P\left(v_{i}=1 \mid v_{i-1}=l_{k}\right)---(2)
\end{aligned}
$$

After there is consideration

$$
=\mathrm{P}\left(\mathrm{t}_{\mathrm{i}}=\mathrm{t} \mid \mathrm{v}_{\mathrm{i}}=1, \mathrm{v}_{\mathrm{i}-1}=\mathrm{l}_{\mathrm{k}}\right)=\mathrm{P}\left(\mathrm{t}_{\mathrm{i}}=\mathrm{t} \mid \mathrm{v}_{\mathrm{i}}=1\right)--(3)
$$

In equation (2) there is process of computing probability about next visit at location 1 .

$\mathrm{P}\left(\mathrm{v}_{\mathrm{i}}=1 \mid \mathrm{v}_{\mathrm{i}-1}=\mathrm{l}_{\mathrm{k}}\right)$ is prior probability about the visit.

$\mathrm{P}\left(\mathrm{t}_{\mathrm{i}}=\mathrm{t} \mid \mathrm{v}_{\mathrm{i}}=1\right)$ is posterior probability.

Also there is categorization of intentions of user [7]. That categorization is as follows:

1) Geographic Triggered Intentions (GI)

2) Temporal Triggered Intentions (TI)

3) Semantic Triggered Intentions (SI)

Geographic Triggered Intentions consider specific location. Suppose there are two consecutive stations A and B. Suppose one person travels from station A then next location can be station B. Temporal triggered intentions considers specific time and location. Suppose at certain time in morning person leaves home and at certain time in evening comes at home. So Temporal triggered Intentions consider certain time and from certain time there can be prediction. Semantic triggered Intentions (SI) considers general consequences of visit. Suppose after leaving offices person goes to Restaurant. Fig-1. Shows Geographic triggered intentions (GI), Temporal Triggered Intentions (TI) and Semantic Triggered Intentions (SI). There is Geographic-Temporal-Semantic-based location prediction GTS-LP [7].GTS-LP predicts the next location based on intensions. If there is set of users and set of locations then location prediction problem can be formulated as calculating probability of user visiting a given location

$\mathrm{F}(1 \mid \mathrm{u}, \mathrm{t}) \longrightarrow[0,1]$

Where $\mathrm{u} \in \mathrm{U}$ and $\mathrm{l} \in \mathrm{L}$ and $\mathrm{t}$ is $\mathrm{u}$ 's current movement [7]. Also there is GTS pattern which is explores aspects of mobile user such as geographical, temporal and sematic aspects. In a GTS pattern there is identification of frequent behaviour of user.
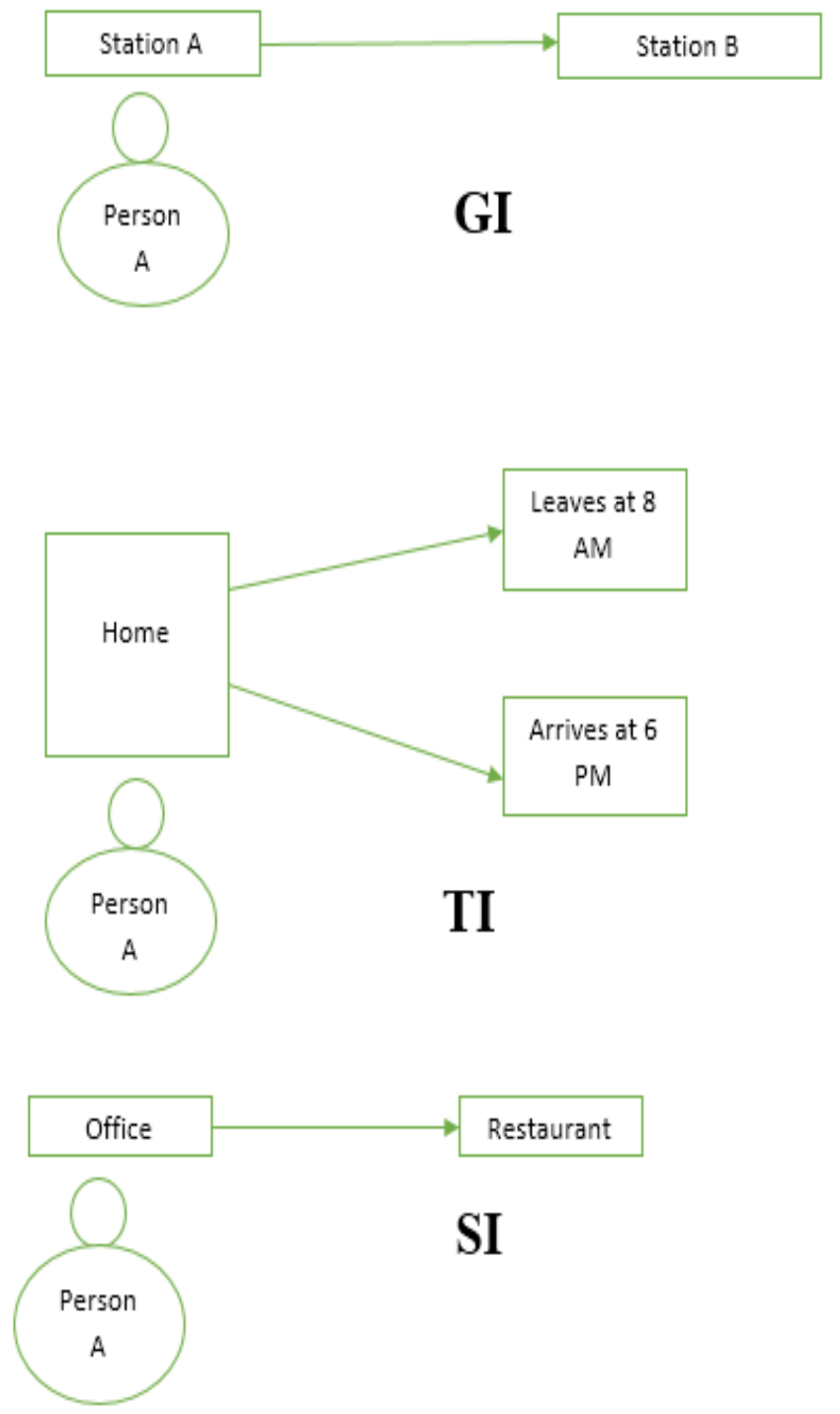

Fig-1 Categorization of Intentions

\subsection{Framework}

There is proposed framework to model user behaviour [4]. Let $\mathrm{u}=\left\{\mathrm{u}_{1}, \mathrm{u}_{2}, \mathrm{u}_{3}, \ldots . ., \mathrm{u}_{\mathrm{n}}\right\}$ set of users and $\mathrm{L}=\left\{\mathrm{l}_{1}, \mathrm{l}_{2}, \mathrm{l}_{3}, \ldots . . \mathrm{lo}\right\}$ is set of locations. Here $n$ is number of users and o is number of locations. So check in represented as $\left\{\mathrm{u}_{\mathrm{a}}, \mathrm{l}_{\mathrm{b}}, \mathrm{t}_{\mathrm{c}}\right\} \in \mathrm{c}$, it indicates that user $u_{a} \in u$ check in at location $l_{b} \in L$ at time tc where $\mathrm{c}$ is the check in set.

Let $f(u)$ is $u$ 's social network friends, $H_{u, t}=\left\{\left\langle u_{a}, l_{b}, t_{c}\right\rangle \mid\right.$ $\left.\left\langle\mathrm{u}_{\mathrm{a}}, \mathrm{l}_{\mathrm{b}}, \mathrm{t}_{\mathrm{c}}\right\rangle \in \mathrm{c}, \mathrm{u}_{\mathrm{a}}=\mathrm{u}, \mathrm{t}_{\mathrm{b}}<\mathrm{t}\right\}$ are $\mathrm{u}$ 's check in actions before time $\mathrm{t}$, and $\mathrm{G}_{\mathrm{u}, \mathrm{t}}=\left\{\left\langle\mathrm{u}_{\mathrm{a}}, \mathrm{l}_{\mathrm{b}}, \mathrm{t}_{\mathrm{c}}\right\rangle \mid\left\langle\mathrm{u}_{\mathrm{a}}, \mathrm{l}_{\mathrm{b}}, \mathrm{t}_{\mathrm{c}}\right\rangle \in \mathrm{c}, \mathrm{u}_{\mathrm{i}} \in \mathrm{f}(\mathrm{u}), \mathrm{t}_{\mathrm{c}}<1\right\}$ are check in actions of friends of $u$ before time $t . t_{c}$ and $t$ are represented in standard time as "yyyy-mm-dd hh:mm:ss $\mathrm{am} / \mathrm{pm}$ "

In Fig-2. There is mobile behavior of $\mathrm{u}$ (as ?) with his history and his friends history. 


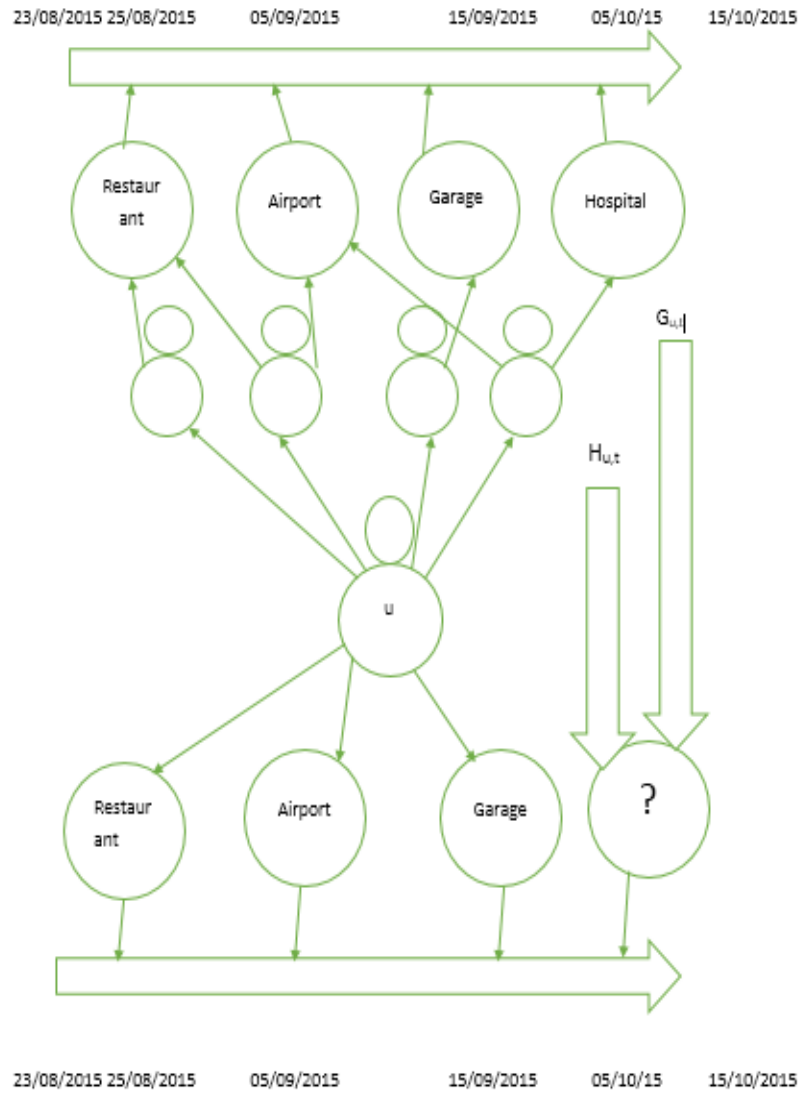

Fig-2 Mobile Behavior of User

Distribution of probability for $\mathrm{u}$ at particular time from observations of $\mathrm{H}_{\mathrm{u}, \mathrm{t}}$ and $\mathrm{G}_{\mathrm{u}, \mathrm{t}}$ there is formula

$\mathrm{P}\left(\mathrm{c}_{\mathrm{u}}=1 \mid \mathrm{t}, \mathrm{H}_{\mathrm{u}, \mathrm{t}}, \mathrm{G}_{\mathrm{u}, \mathrm{t}}\right)$

Here $c_{u}$ is for check in of user u's location.

After that there is temporal state which is denoted by $r(t) . r(t)$ $\sum\{0,1,2 \ldots .23\}$ for indication of time. If $\mathrm{r}(\mathrm{t})=2$ it indicates time $2 \mathrm{am}$.

Also $r(t) \sum\{0,1,2, . .6\}$ for week. So equation (1) with temporal state can be reformulated as

$\left.\mathrm{P}\left(\mathrm{c}_{\mathrm{u}}=1 \mid \mathrm{r}(\mathrm{t})\right), \mathrm{H}_{\mathrm{u}, \mathrm{t}}, \mathrm{G}_{\mathrm{u}, \mathrm{t}}\right)$

So by applying Bayes' rule

$$
\left.\mathrm{P}\left(\mathrm{c}_{\mathrm{u}}=1 \mid \mathrm{r}(\mathrm{t})\right), \mathrm{H}_{\mathrm{u}, \mathrm{t}}, \mathrm{G}_{\mathrm{u}, \mathrm{t}}\right)
$$

$\propto p\left(r(t) \mid c_{u}=1, H_{u, t}, G_{u, t}\right) p\left(c_{u}=1 \mid H_{u, t}, G_{u, t}\right)$

From the above equation there is decomposition of check in probability in two components with respect to spatial and temporal context.

\subsection{Modelling for temporal cyclic patterns}

To model temporal preferences at location $\mathrm{P}(\mathrm{r}(\mathrm{t})=\mathrm{q}$ | $\mathrm{cu}=1, \mathrm{Hu}, \mathrm{t})$ there is need of probability distribution, that distribution should satisfy the following [4]:

1) Centers of probability distribution on temporal states.

2) Decrease in probability as the distance from center point increases.

3) For each user has a decrease in speed around center for biased probability.

For this there is Gaussian Mixture Model (GMM) to detect temporal preferences.

\section{SPATIAL MODELS}

There are spatial models, which makes use of location trajectory pattern for prediction of location [4]. That models are

1) Most frequent check in model: In this model social information is not used.

2) Order-1 Markov model (OMM): This model examine frequent patterns for prediction.

3) Social Historical Model (SHM): This model makes use of historical Pitman-Yor model for prediction.

Geo Social Correlation: for user behavior there can be existing check-ins and new check-ins [5]. Existing check-ins can be correlated with user's historical ties and social ties. When there is new check-ins, which can be from social check-ins. So there is chance to study such correlation, so that it can help for location prediction problem.

As shown in below Fig-3 if user goes to airport at t1, after that at $\mathrm{t} 2$ he goes to restaurant followed by hospital at $\mathrm{t} 3$.

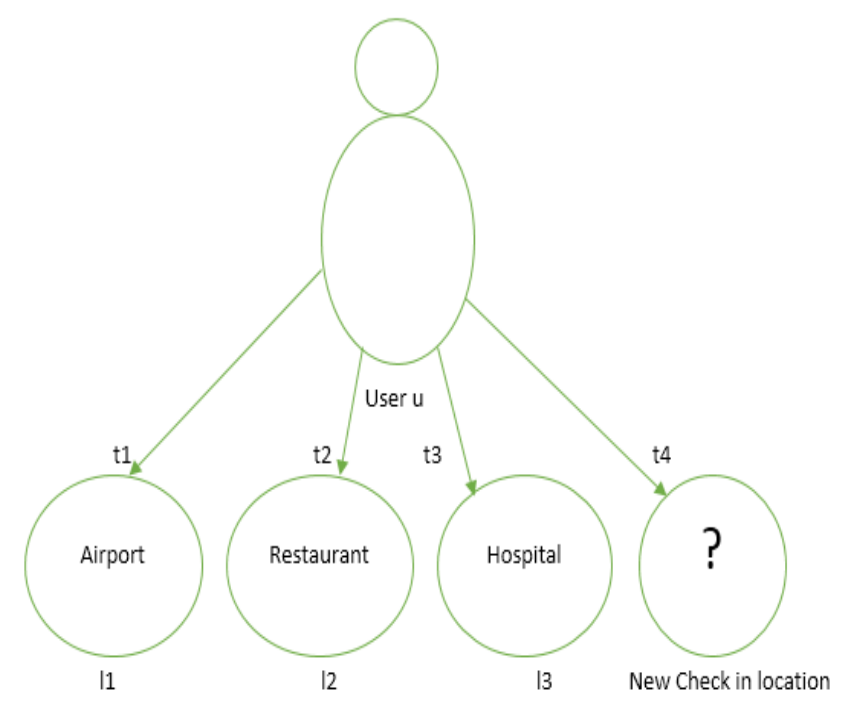

Fig-3 Geo Social Correlation

\section{CONCLUSIONS}

This paper gives information about the temporal patterns and information related to temporal spatial patterns. Also there is information related to algorithms that are useful for temporal pattern mining. There is information about applications of temporal cyclic patterns. Also this paper gives information about the location prediction. Temporal pattern gives information about the user's behavior and from that behavior there can be identification of user's need and interests.

\section{REFERENCES}

[1] Yi-Cheng Chen, Wen-Chih Peng and Suh-Yin Lee, 'Mining Temporal Patterns in Time Interval-Based Data,' Knowledge and Data Engineering, IEEE Transactions, pp. 3318 - 3331, 09 July 2015.

[2] Huiji Gao, Jiliang Tang, Xia Hu, and Huan Liu, 'Exploring Temporal Effects for Location Recommendation on Location-Based Social Networks', 
ACM New York, NY, USA @2013, pp. 93-100, 201310-12.

[3] Huiji Gao, Jiliang Tang and Huan Liu, 'Mobile Location Prediction in Spatio-Temporal Context', Nokia Mobile data Challenge Workshop, 2012.

[4] Huiji Gao, Jiliang Tang, Xia Hu, and Huan Liu, 'Modeling Temporal Effects of Human Mobile Behavior on Location-Based Social Networks', ACM New York, NY, USA @2013, pp. 1673-1678, 2013-1027.

[5] Huiji Gao, Jiliang Tang, Huan Liu, 'gSCorr: Modeling Geo-Social Correlations for New Check-ins on Location Based Social Networks, ' ACM New York, NY, USA @2012, pp. 1582-1586, 2012-10-29.

[6] Mikhail Zolotukhin, Elena Ivannikova and Timo H“am"al"ainen, "Novel Method for the Prediction of Mobile Location Based on Temporal-Spatial Behavioral Patterns,' Information Science and Technology (ICIST), 2013 International Conference, pp. 761 - 766, 23-25 March 2013.

[7] JOSH JIA-CHING YING, WANG-CHEIN LEE, VINCENT S. TSENG, 'Mining Geographic-TemporalSemantic Patterns in Trajectories for Location Prediction, 'ACM New York, NY, USA, 33 pages, 2013-12-01. 